\title{
BMJ Open Stick or twist? Career decision-making during contractual uncertainty for NHS junior doctors
}

\author{
S Spooner, ${ }^{1}$ Jon Gibson, ${ }^{1}$ Dan Rigby, ${ }^{2}$ Matt Sutton, ${ }^{1}$ Emma Pearson, ${ }^{1}$ \\ Kath Checkland ${ }^{1}$
}

To cite: Spooner S, Gibson J, Rigby D, et al. Stick or twist? Career decision-making during contractual uncertainty for NHS junior doctors. BMJ Open 2017;7:e013756. doi:10.1136/bmjopen-2016013756

- Prepublication history and additional material is available. To view please visit the journal (http://dx.doi.org/ 10.1136/bmjopen-2016013756).

Received 5 August 2016 Revised 14 December 2016 Accepted 20 December 2016

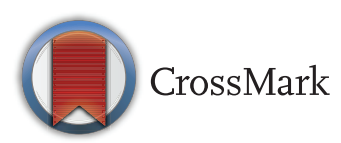

\footnotetext{
${ }^{1}$ Division of Population Health, The University of Manchester, Health Services Research \& Primary Care, Manchester, UK

${ }^{2}$ Economics, The University of Manchester, Manchester, UK
}

\section{Correspondence to}

Dr S Spooner;

sharon.spooner@manchester. ac.uk

\section{ABSTRACT}

Objectives: To examine the extent, and nature, of impact on junior doctors' career decisions, of a proposed new contract and the uncertainty surrounding it.

Design: Mixed methods. Online survey exploring: doctors' future training intentions; their preferred specialty training (ST) programmes; whether they intended to proceed immediately to ST; and other plans. Linked qualitative interviews to explore more fully how and why decisions were affected.

Setting: Doctors (F2s) in second year of Foundation School (FS) Programmes in England.

Participants: Invitations sent by FSs. Open to all F2s November 2015-February 2016. All FSs represented. Survey completed by 816 F2s. Sample characteristics broadly similar to national F2 cohort.

Main outcome measures: Proportions of doctors intending to proceed to ST posts in the UK, to defer or to exit UK medicine. Proportion of doctors indicating changes in training and career plans as a result of the contract and/or resulting uncertainty. Distribution of changes across training programmes. Explanations of these intentions from interviews and free text comments. Results: Among the responding junior doctors, 20\% indicated that issues related to the contract had prompted them to switch specialty and a further $20 \%$ had become uncertain about switching specialty. Switching specialty choice was more prevalent among those now choosing a community-based, rather than hospital-based specialty. $30 \%$ selecting general practice had switched choice because of the new contract. Interview data suggests that doctors felt they had become less valued or appreciated in the National Health Service and in society more broadly.

Conclusions: Doctors reported that contract-related issues have affected their career plans. The most notable effect is a move away from acute to community-based specialities, with the former perceived as more negatively affected by the proposed changes. It is concerning that young doctors feel undervalued, and this requires further investigation.

\section{INTRODUCTION}

In the winter/spring of 2015/2016 junior doctors in England took unprecedented

\section{Strengths and limitations of this study}

- Sample characteristics are broadly similar to cohort as a whole, subanalysis to probe genderrelated responses.

- Data were collected at a pivotal stage of career planning and during an unprecedented industrial dispute. We do not know the extent to which intended career plans will be realised.

- The study design (including linked qualitative work) allowed us to explore in more detail the factors underlying the survey findings.

- Survey responses were received from $12.6 \%$ of eligible participants $(n=816)$. While this may appear low, it is comparable with response rates to other surveys recruiting via email invitations.

- It is possible that those most concerned about the stability or security of their future career may have responded in greater numbers and that this subgroup may have greater concerns about the implications of the contract dispute.

strike action in protest against the terms of a proposed new contract. ${ }^{1}$ Over many months, the dispute played out in public via conflicting statements from the Department of Health and the British Medical Association (the doctors' trade union) alongside commentary in mass and social media. In the midst of this noise and uncertainty, a cohort of early career doctors (Foundation Programme Year 2 doctors, F2s) across England were making their choice of specialty training programme.

In this paper, we report results from a mixed methods study which included a national survey of F2 doctors and linked qualitative interviews. Data were collected during this period of future contractual uncertainty and an ongoing dispute, and reveal how the training choices, and longterm career plans, of doctors applying for specialist training programmes were affected by the new contract and surrounding 
uncertainty. We will identify and discuss the implications of our results for the long-standing problem of under recruitment in certain specialties, most notably general practice.

\section{Specialty training in the UK}

On completing medical school, newly qualified doctors in the UK undertake 2 years of preliminary practice prior to full admission to the medical register, known as 'foundation training'. At the end of the second year (F2) they are eligible to enter specialty training. In 2005 there was a comprehensive overhaul of specialty training in the UK, known as Modernising Medical Careers (MMC). The main elements of the reforms included centralised application processes, shorter training programmes and 'run through' training for some specialities, which removed the need to reapply for completion of training in higher specialities after a period of basic training. MMC also reduced the flexibility to move between specialities. These changes were not uncontroversial, and have been subject to ongoing criticism. ${ }^{2}{ }^{3}$ Those doctors who do not proceed to specialty training may work in the National Health Service (NHS) in nontraining posts, which do not count as accrued experience towards their eventual qualification. In recent years the proportion of F2s not immediately proceeding to a specialist training programme has risen from $28.7 \%$ in 2011 to $48 \%$ in $2015 .{ }^{4}$

\section{The contractual negotiations}

Employment contracts for NHS doctors in training (aka junior doctors) came under review following a scoping study undertaken by NHS Employers, ${ }^{5}$ and a subsequent report by the Doctors and Dentists Review Body (a body responsible for setting levels of pay for doctors and dentists in England). ${ }^{6}$ Both concluded that existing contracts were neither fully fit for purpose nor adequate for future service needs. Full renegotiation of junior doctors' contracts was recommended. Among the objectives of a new contract were: better patient care; more engaged and valued doctors; affordability; improved relationships between doctors and employers; and building the next generation of medical professionals. ${ }^{56}$

Mutual distrust was evident in the discussions between the Department of Health (DH) and professional representatives with disagreement on many points, ${ }^{7}$ and these disagreements were publicly debated by both parties. While the DH spoke of improving outcomes for patients admitted to hospital at weekends, ${ }^{8}$ junior doctors voiced concern about risks to patient and doctor safety due to proposed onerous working hours, which they argued would be less rigorously policed under the new system.

Concerns were raised that changes to the definition of, and pay rates for, 'standard' and 'antisocial' hours would further disincentivise less-popular career options (eg, emergency medicine) despite the introduction of 'premia' to boost their attractiveness. ${ }^{9}$ Also, those undertaking training in specialties where non-resident on-call duty is expected, would receive reduced payments for the hours when they must nonetheless be available for work. This arguably would reduce expected income while the potential for disruption could continue to affect family life. ${ }^{10}$ It was argued that switching from a system where pay increases were based on accrued experience, to one based on progression through training levels, would disproportionately affect doctors changing from one training programme to another or taking time out for family, health or other reasons. Claims that selective penalising of doctors for time away from fulltime work failed to meet expected equality standards, ${ }^{11} 12$ were countered in a DH paper which stated: 'Any indirect adverse effect which may occur is a proportionate means of achieving a legitimate aim'. ${ }^{13}$ The contract was also criticised for generating unrealistic rotas, for use of an online pay calculator which produced erroneous figures and lack of awareness that existing patterns of work already often exceeded doctors' contracted hours. ${ }^{1415}$

Doctors began speaking out about the contract's implications for safe working, financial consequences and projections of insufficient recruitment to ensure full junior doctors' rotas. ${ }^{16}$ As talks broke down, the Health Secretary announced that the new contract would be introduced without agreement, further fuelling the dispute. ${ }^{17} 18$ Junior doctors undertook a series of unprecedented strikes across England between 12th January and 27th April 2016, ${ }^{19}$ with evidence of much public support, with support from senior doctors who provided medical cover during strike action and with attempts by the Academic Royal Colleges to effect resolution. ${ }^{20-22}$ At present, opposing parties remain in disagreement over implementation of the terms of the new contract, with junior doctors recently rejecting the terms of the negotiated contract, which is now set to be introduced without agreement in the autumn of 2016.

\section{Study aims}

The overall aim of the study is to explore how junior doctors think about their career choices, and the factors which affecting this. The timing of the study-in the middle of a contractual dispute-was serendipitous, allowing us to also explore how factors related to the proposed new contract were feeding into the decisionmaking process for this cohort of doctors. In this paper, our aim is to examine how the proposed new contract and related issues have affected applications across different specialty training (ST) programmes and its potential impact on the longer-term career plans of doctors completing foundation training.

We examine the choice of preferred specialty and the prevalence of alternative responses to factors related to the new contract. These include changing choice of specialty (switch); deferring the training choice (defer); planning to work overseas after training (train and leave); exiting UK medical training (exit) and no change to specialty choice (stick). We investigate junior 
doctors' perceptions of, and plans for, their future career working in the UK as affected by these issues. This is particularly important because the high-profile nature of the dispute as a reaction to the new contract means that its potential impact may not be limited to those currently affected. Medical students, those considering applying to medical school and junior doctors at earlier stages of training will also be influenced by the arguments being made in the media and among the doctors with whom they come into contact. Mitigating any longer-term impacts requires a clear understanding of who might be affected and in what ways. The design of this study, with survey responses contextualised by in-depth qualitative interviews, provides early evidence to inform this process, and suggests future avenues of research to support the declared DH policy aim of increasing recruitment and retention into the medical workforce.

\section{METHODS}

In late 2015, a cohort of junior doctors across England was approaching completion of a series of community and hospital rotations during a 2-year postqualification programme and preparing to apply for their preferred ST programme against a disruptive backdrop of debates about their future employment contract. These doctors were invited to complete a national survey about their (intended or submitted) applications for specialist training and the effects of the contract dispute on their plans. Owing to continuing fluidity of contract negotiations and plans for industrial action, our questions were intended to capture responses generated by the terms of and uncertainty surrounding the new contract; that is, we asked whether decisions and choices were affected by 'recent uncertainties and proposed changes in contracts for junior doctors'. Hence, we cannot ascertain the extent to which each of these may have independently contributed to doctors' decision-making this paper reports on these dual aspects of the contract and uncertainty surrounding it. Survey questions are provided in the online supplementary appendix.

Data were collected from doctors in the second year of postqualification training (F2). Invitations to participate were sent during the period when they were preparing and submitting applications to ST programmes. Email invitations were sent by the 19 Foundation Schools (FS) in England who deliver training to Foundation doctors and supervise successful attainment of foundation training requirements. The study was comprised of two components: an online, largely quantitative, survey with follow-up in-depth qualitative interviews.

\section{Survey}

All F2 doctors in England were eligible to complete the online survey and we worked with FS directors to have emails or eportfolio messages sent between October 2015 and February 2016. Accompanying information advised participants that entry to a Prize Draw was available on completion of the survey. No additional incentives were available for participating in interviews and the invitation did not mention the junior doctor contract dispute.

In the absence of direct access to F2 doctors' email addresses, dissemination of invitations and reminders was processed by FS managers and administrators according to the mailing and messaging preferences of each FS. Despite requesting that the same invitations and reminders were sent in each FS, response rates varied from $5 \%$ to $24 \%$ in a pattern which did not demonstrate a discernible relationship with the geography of regional boundaries. Where individual FS response levels appeared low, we directly contacted FS staff to check that invitations were being sent out. Since we could not guarantee universal coverage by this process, social media messages were used to advise doctors to look for their personal invitation; however, we remained uncertain about the proportion of F2s who actually received or opened a message about the survey.

Respondents reported on demographic detail alongside information about their medical education and training. The survey asked doctors to select all specialty training programmes that they intended to apply for, or had already applied for and to indicate which one of these chosen programmes was their first preference.

Given that the proportion of F2s not immediately applying for specialist training programmes has been increasing, we asked whether, rather than proceed immediately to a specialist training programme, they intended to defer future training or to exit from medical training. They also indicated whether they intended to move to work overseas after their training and whether contract-related issues had caused them to switch training choice.

Survey design was an iterative process involving a review of the relevant literature, discussion of factors affecting career choices, with F2s and general practitioners (GPs) working alongside junior doctors. The survey was piloted in depth with five doctors of similar career stage and further refinement was based on their feedback.

Where appropriate screening questions were used to tailor subsequent survey questions according to specific decisions, responses and situations for each respondent. Participants indicated the extent to which their choices were affected by the new contract, and which aspects of proposed contract changes troubled them most, via both quantitative and free text questions.

\section{Interviews}

On completion of the online survey, all respondents were asked to indicate their willingness to be contacted for an individual follow-up interview to explore the reasons behind their expressed preferences. Purposive sampling of the resulting cohort was employed to sample for maximum variation (selection criteria included; gender, preferred specialism, places of 
undergraduate and postgraduate study, whether participants had a GP parent, when participants chose their preferred specialism).

A set of 20 individual, face to face, narrative interviews were audio recorded with 6 men and 14 women (reflecting the gendered imbalance of consent to participate in interviews and availability) with doctors preferring a broad range of specialties. The average interview duration was 62 min (range 43-83). Participants were encouraged to develop narrative accounts of events and experiences which had influenced their career choices and to comment on whether the contract dispute contributed to that process. The interview stage ended when a lack of new emerging themes was attributed to data saturation.

\section{Analysis}

Data from three components of the study have been analysed;

1. Numerical and categorical survey responses (survey);

2. Free-text comments (survey);

3. Qualitative individual interviews.

We examined the proportion of survey respondents indicating that factors related to the new contract had affected their decisions, and how this differs over observable characteristics (such as training choice). All statistical analyses, including tests on the equality of proportions and generation of CIs, were conducted using Stata V.14.

Audio recordings of all interviews were anonymised and transcribed verbatim. Qualitative analysis of free-text survey comments and interviews proceeded using an inductive approach to semantic thematic analysis, following steps set out by Braun and Clark. ${ }^{23}$ NVivo software was used to code emerging themes.

There is wide variation in the number of training places available across different ST programmes and few survey respondents select those programmes with lower levels of capacity (see table 1). Taking this into account, and in common with previous studies which grouped training programmes according to traditional patterns or perceived similarities, ${ }^{24}{ }^{25}$ we grouped the programmes to facilitate analysis and interpretation.

Given our focus on the perceived differential effects of the proposed contract, and informed by preliminary analysis of free-text comments from $\mathrm{F} 2$ respondents, the specialist programmes are grouped according to the (perceived) differential impacts of the contract on them. Thus, for example, acute medical specialities where the 'standard' component of evening and weekend duties would increase, may be more affected by redefinition of hours than other specialties in hospital or community settings where different working patterns would lessen the effects of this change.

Three groups of programmes were identified: acute hospital specialties; other hospital specialties; and community-based specialties. The specialities comprising each of the three groups, the number of training places available for each of them, and the distribution of survey respondents' first choices across them are listed in table 1. This categorisation is used to differentiate the survey responses in the reporting and discussion that follows.

Table 1 Categorisation of survey respondents' preferred specialty training programmes and available training places in 2016

\begin{tabular}{|c|c|c|c|c|c|}
\hline \multirow[b]{2}{*}{ Training programme } & \multirow[b]{2}{*}{ Categorisation } & \multicolumn{2}{|c|}{$\begin{array}{l}\text { Places made } \\
\text { available by } \\
\text { HEE for } 2016^{\star}\end{array}$} & \multicolumn{2}{|c|}{$\begin{array}{l}\text { 1st preference } \\
\text { for application } \\
\text { (our survey) }\end{array}$} \\
\hline & & $\overline{\mathbf{n}}$ & Per cent & $\mathbf{n}$ & Per cent \\
\hline ACCS Emergency Medicine & Acute hospital specialties & 298 & 5 & 48 & 7 \\
\hline Anaesthetics and ACCS Anaesthetics & & 459 & 8 & 90 & 12 \\
\hline Core Medical Training and ACCS Acute Medicine & & 1036 & 18 & 162 & 22 \\
\hline Core Surgical Training & & 506 & 9 & 62 & 8 \\
\hline Obstetrics and Gynaecology & & 209 & 4 & 32 & 4 \\
\hline \multirow[t]{2}{*}{ Paediatrics and Child Health } & & 316 & 5 & 61 & 8 \\
\hline & Total & 2824 & 49 & 455 & 62 \\
\hline Cardiothoracic Surgery & Other hospital specialties & 5 & 0.1 & 3 & 0.4 \\
\hline Clinical Radiology & & 205 & 4 & 26 & 4 \\
\hline Histopathology & & 65 & 1 & 14 & 2 \\
\hline Neurosurgery & & 22 & 0.4 & 5 & 1 \\
\hline Ophthalmology & & 60 & 1 & 11 & 1 \\
\hline Oral and Maxillofacial Surgery & & 3 & 0.1 & 1 & 0.1 \\
\hline \multirow[t]{2}{*}{ Psychiatry } & & 280 & 5 & 37 & 5 \\
\hline & & 640 & 11 & 97 & 13 \\
\hline Community Sexual and Reproductive Health & Community-based specialties & 5 & 0.1 & 8 & 1 \\
\hline General Practice & & 2296 & 39 & 167 & 23 \\
\hline \multirow[t]{3}{*}{ Public Health } & & 56 & 1 & 8 & 1 \\
\hline & Total & 2357 & 40 & 183 & 25 \\
\hline & Total & 5821 & & 735 & \\
\hline
\end{tabular}




\section{Sample characteristics}

Complete responses were received from 816 F2 doctors (12.6\% of the total cohort of 6470).

Sample characteristics were compared to the limited publicly-available information on this cohort. The sample includes more women $(65 \%)$ than the same cohort during their first year (F1) of FS training $(56 \%),{ }^{26}$ this imbalance among respondents is addressed later in the paper.

Respondents who stated they would not proceed to future medical training $(n=33)$ were asked to indicate their reasons for leaving but, since they did not supply information about a future medical career, they have been omitted from those sections of the analysis.

We dropped a number of responses due to the withdrawal of their preferred training option (Broad-Based Training $(n=9))$, failure to state a preferred ST option $(n=5)$ or selection of 'Other' $(n=34)$ rather than one of the programme options. The latter were predominately doctors seeking a career in academia, leaving medicine or joining the armed forces.

\section{Findings}

In this section, we set out the broad picture of career choices before detailed presentation of our findings is organised around the possible 'mitigating responses' related to the contract. In each subsection, we present evidence from the survey, alongside relevant contextual evidence from either the free-text section of the survey or the qualitative interviews.

\section{Choice of specialty}

A quarter of the sample's first choice was for training leading to work in a community role. The majority (167) of these 183 respondents were applying to general practice. Core Medical Training/ACCS Acute Medicine was the other programme which, together with general practice, dominated doctors' first preferences. Anaesthetics and ACCS Anaesthetics was the third most popular specialist area, but had half as many applicants as the top two.

There are notable imbalances between the proportion applying as first preference and the proportion of places available. Demand for places outstrips supply in Paediatrics and Core Medical programmes. There is a substantial mismatch in general practice, which represents $39 \%$ of the places available but which only $23 \%$ of respondents had chosen as a first preference.

\section{Responses to proposed contract}

Doctors in training could respond to the proposed contract by sticking with their training choice, or twisting; by switching from one specialty to another, exiting, deferring or training but then leaving the UK. We show how the prevalence of these varies over the three types of programme identified in table 1 and we use respondents' responses, from free-text questions in the survey and the personal interviews, to reveal the motives and meanings of these responses.
Mitigating response A-leave medical work or do not plan to apply for specialist training in the UK

A number of respondents indicated that contract issues had made them question their career in medicine entirely. Of the 816 survey respondents, 318 (39\%) did not intend to apply for a training place to start in 2016. Of these, 33 (4\% of the total sample) stated they did not intend to apply for training to start after 2016. The remainder were uncertain or expected to submit an application after the 2016 recruitment cycle. Motivations for decisions to exit included:

\begin{abstract}
'The junior contract issues made me question seriously whether I should stay in medicine as opposed to affect the choice of specialty' (Survey ID 39)

'Considering whether alternative careers may be an option, given that it looks like being a doctor now isn't quite the job I signed up for' (Survey ID 131)
\end{abstract}

\section{Mitigating response B-defer application for ST until contract issues become clearer}

High rates of deferral among previous cohorts indicate that deferring predates the contract dispute. However, the survey responses displayed in table 2 indicate a contract-related effect among this year's cohort of F2s. The numbers and proportions opting to defer, in table 2, are disaggregated by the F2's first preference specialty group.

The proportion of F2 respondents planning to defer further training was significantly higher among those applying for an acute hospital programme (table 2). About $41.1 \%{ }^{\mathrm{i}}$ of those applying to an acute hospital programme indicated that they intended to defer compared to $26.2 \%$ ii intending to apply for community posts.

Of the $34.7 \%(18.1 \%+16.6 \%)$ of participating doctors who intended to defer application for further training, $48 \%$ indicated that their deferral was related, to some extent, to the ongoing contract issues. Of those intending to defer, a higher proportion of those applying to acute hospital-related training courses reported that contract-related factors affected their decision $(49.7 \%)^{\text {iii }}$ relative to those deferrers intending to apply for community-based roles $(41.7 \%)^{\text {iv }}$. The difference between these groups is $8 \%(95 \% \mathrm{CI}-7.6 \%$ to $23.7 \%)$.

Interview and free text data confirmed that doctors were aware that it would be difficult to switch from one training programme to another and expected this to become even more difficult under the new contract. Making a good career choice was therefore seen as very important and they were prepared to invest time or

$\mathrm{i}_{20.7 \%}+20.4 \%$

${ }^{\text {ii }} 15.3 \%+10.9 \%$

The difference between 1 and 2 is $14.9 \%$ (95\% CI $7.1 \%$ to $22.7 \%$ )

iii $(93 /(94+93)) \times 100$

${ }^{\text {iv }}(20 /(28+20)) \times 100$

The difference between 3 and 4 is $8 \%$ (95\% CI $-7.6 \%$ to $23.7 \%$ ) 
Table 2 Decision to defer further training by preferred specialty group among F2 respondents

\begin{tabular}{|c|c|c|c|c|c|c|c|c|c|}
\hline & \multicolumn{2}{|l|}{$\begin{array}{l}1 \text { Acute } \\
\text { hospital }\end{array}$} & \multicolumn{2}{|l|}{$\begin{array}{l}2 \text { Other } \\
\text { hospital }\end{array}$} & \multicolumn{2}{|c|}{3 Community } & \multicolumn{2}{|l|}{ Total } & \multirow{2}{*}{$\begin{array}{l}\text { Difference between } \\
1 \text { and } 3 \text { (\% points) }\end{array}$} \\
\hline & Number & Col \% & Number & Col \% & Number & Col \% & Number & Col \% & \\
\hline No plans to defer & 268 & 58.9 & 77 & 79.4 & 135 & 73.8 & 480 & 65.3 & $-14.9(-22.7$ to -7.1$)$ \\
\hline $\begin{array}{l}\text { Defer (uncertain or no } \\
\text { contract impact) }\end{array}$ & 94 & 20.7 & 11 & 11.3 & 28 & 15.3 & 133 & 18.1 & $5.4(-1.0$ to 11.8$)$ \\
\hline Defer (contract impact) & 93 & 20.4 & 9 & 9.3 & 20 & 10.9 & 122 & 16.6 & 9.5 (3.7 to 15.4$)$ \\
\hline Total & 455 & 100 & 97 & 100 & 183 & 100 & 735 & 100 & \\
\hline
\end{tabular}

$95 \% \mathrm{Cls}$ are provided in ().

travel overseas to broaden their experience before applying:

Personally, I think less than 2 years in employment is too short a period to make a decision on the entirety of my future career path. Especially, as I feel there is little flexibility to change between specialities. (Survey ID 13)

F2s reported that they had initially been undecided as to whether to defer, but the contract issues have weighted their decision towards delaying application:

I am not applying this year. I was unsure before, but the issues with contracts for juniors has [sic] helped me make up my mind. (Survey ID 42)

Some indicated that concerns about working antisocial hours, negative effects on work-life balance and a different mechanism to calculate pay, had reduced their desire to train in acute specialties:

There is a lot of uncertainty about the 2016 contract. I would rather wait and see what ends up happening before choosing a career path as my two options include $\mathrm{A}+\mathrm{E}$ and GP both of which could be drastically affected (Survey ID 310)

Furthermore, for those whose first choice was a community role, contract matters were also a factor for about half of the deferrers $(20 / 41)$ :

I was always going to think about it. I mean, I don't think I was always going to be 100 per cent definitely going not to apply, but I think with recent contract changes and the state that the NHS is in at the moment it's just even more reason to have a year out of medicine.' (Interview IDGP1P1)

\section{Mitigating response C_proceed to preferred specialty but plan to leave the UK later}

About 14.8 per cent $^{\mathrm{v}}$ of F2 doctors applying for training posts indicated they were planning to move overseas after further training (table 3).

Among the $14.8 \%$ of the sample who revealed they were 'likely' or 'very likely' to move abroad after their training, the vast majority $\left(84 \%{ }^{\mathrm{vi}}\right)$ indicated that this decision to (likely) move abroad was related to the contract situation. The likelihood of moving abroad due to contract issues was higher among the acute specialities ( $13.6 \%$ vs $9.8 \%)$, but the difference was not statistically significant $(3.8 \%(95 \% \mathrm{CI}-1.6 \%$ to $9.4 \%))$

Doctors spoke of a range of reasons which attracted them to explore global opportunities in medicine:

\section{Work-life balance}

I really don't know. If the new contracts go through I will seriously consider emigration as I don't think the work life balance will be sustainable. (Survey ID 107)

I did my medical school elective in New Zealand and found that the staff working in the hospital had a good work/life balance, worked fair and safe hours and felt appreciated by the departments they worked in. This is a much more attractive working prospect than working in the NHS if the new junior contracts are forced through. (Survey ID 201)

\section{Personal/family connections}

I will probably leave the UK after a few years of Training!! I have strong family connections outside of the UK and plan to leave the UK Soon! (Survey ID 416)

I have family who are Dr's in Australia and the difference in enjoyment, work satisfaction, time allocated to private study and learning and work-life balance are huge. They have also spent some time working in the NHS so they are able to make a direct comparison. (Survey ID 661)

\section{Constraints on careers}

Changes to contract have made me more encouraged to complete GP training ASAP! I would like the freedom to travel and perhaps have more of a portfolio career so I am less beholden to this country's politics and policies. (Survey ID 164)

I may start specialist training in the UK but changes in the contract means I am considering continuing training abroad. (Survey ID 468) 
Table 3 Decision to leave the UK to further career by preferred specialty group

\begin{tabular}{|c|c|c|c|c|c|c|c|c|c|}
\hline & \multicolumn{2}{|l|}{$\begin{array}{l}1 \text { Acute } \\
\text { hospital }\end{array}$} & \multicolumn{2}{|l|}{$\begin{array}{l}2 \text { Other } \\
\text { hospital }\end{array}$} & \multicolumn{2}{|c|}{3 Community } & \multicolumn{2}{|l|}{ Total } & \multirow{2}{*}{$\begin{array}{l}\text { Difference } \\
\text { between } 1 \text { and } 3\end{array}$} \\
\hline & Number & Col \% & Number & Col \% & Number & Col \% & Number & Col \% & \\
\hline $\begin{array}{l}\text { Likely or very likely stay in } \\
\text { UK or unsure }\end{array}$ & 378 & 83.1 & 86 & 88.7 & 162 & 88.5 & 626 & 85.2 & $-5.4(-11.2$ to 0.3$)$ \\
\hline $\begin{array}{l}\text { Likely or very likely move } \\
\text { abroad (no contract issue) }\end{array}$ & 15 & 3.3 & 0 & 0 & 3 & 1.6 & 18 & 2.4 & $1.6(-0.2$ to 4.1$)$ \\
\hline $\begin{array}{l}\text { Likely or very likely move } \\
\text { abroad (contract related) }\end{array}$ & 62 & 13.6 & 11 & 11.3 & 18 & 9.8 & 91 & 12.4 & $3.8(-1.6$ to 9.1$)$ \\
\hline Total & 455 & 100 & 97 & 100 & 183 & 100 & 735 & 100 & \\
\hline
\end{tabular}

\section{Advice from colleagues}

Several senior colleagues, consultants and GPs I have worked with have all said the same thing-move abroad. This is extremely disheartening to hear from colleagues you admire but unfortunately it seems to be more and more true. (Survey ID 661)

\section{Mitigating response D-switch to a training programme} which may be less adversely affected by the new contract The numbers of F2s who had switched specialty programme choice, split by their final preferred ST choices, are shown in table 4 .

F2s now intending to apply for a community role were more likely to have changed their first preference because of the contract situation than F2s now intending to apply for an acute role $(30.1 \%$ vs $16.5 \%$, difference $=13.6 \%$ (95\% CI $21 \%$ to $6.1 \%))$. Those who currently intend to apply to an acute hospital role are significantly more uncertain regarding switching their training choice than those currently considering applying to a community role $(22.9 \%$ vs $15.3 \%$, difference $=7.6 \%$, $95 \%$ CI $1.1 \%$ to $14 \%$ ).

In free text sections of the survey and during interviews, doctors revealed that they were now more likely to consider a community role in light of the contract issues. For doctors who had intended to train in specific acute specialties, the perceived disadvantages of duration of training or expected working patterns made them rethink their plans;

[Paediatrics] has longer specialist training than GP so if the proposed contract changes go through I am more likely to choose GP (Survey ID 513)

My first choice had always been core medical training. However, contracts have put this into third choice as clinical radiology and general practice are both run-through schemes with CCT as a result of the end of training. (Survey ID 353)

There was evidence that doctors who had intended to begin specialist training despite feeling uncertain about it, were now too concerned about the consequences of trying that choice that they were prepared to change their plans:

I know a lot of people that haven't applied because they aren't sure and they don't want to try two years of core training for medicine, because if they don't like it and they reapply for GP they'll take a pay cut. I know a lot of people have changed their career plans based on that this year, unfortunately.' (Interviewee ID GP1P1)

In some cases, they indicated why previously unattractive specialisms were considered as a less-unattractive

Table 4 Decision to switch first choice specialism because of contract changes and uncertainty by current preferred specialty group

\begin{tabular}{|c|c|c|c|c|c|c|c|c|c|}
\hline & \multicolumn{2}{|c|}{1 Acute hospital } & \multicolumn{2}{|c|}{2 Other hospital } & \multicolumn{2}{|c|}{3 Community } & \multicolumn{2}{|l|}{ Total } & \multirow{2}{*}{$\begin{array}{l}\text { Difference } \\
\text { between } 1 \text { and } 3\end{array}$} \\
\hline & Number & Col \% & Number & Col \% & Number & Col \% & Number & Col \% & \\
\hline $\begin{array}{l}\text { Switch because of } \\
\text { contract issues }\end{array}$ & 75 & 16.5 & 21 & 21.6 & 55 & 30.1 & 151 & 20.5 & $-13.6(-21$ to -6.1$)$ \\
\hline $\begin{array}{l}\text { Not switch because of } \\
\text { contract issues }\end{array}$ & 276 & 60.7 & 65 & 67 & 100 & 54.6 & 441 & 60 & $6.1(-2.5$ to 14.5$)$ \\
\hline $\begin{array}{l}\text { Uncertain whether to } \\
\text { switch because of } \\
\text { contract issues }\end{array}$ & 104 & 22.9 & 11 & 11.3 & 28 & 15.3 & 143 & 19.5 & 7.6 (1.1 to 14$)$ \\
\hline Total & 455 & 100 & 97 & 100 & 183 & 100 & 735 & 100 & \\
\hline
\end{tabular}


option, including their expectation of end point rewards.

Due to changes in contract and training, I am reconsidering a surgical career where pay progression and work-life balance play a huge factor. I am therefore reconsidering and have applied for GP where the work life balance is better and after training I could be on the same wage as a Consultant (which would take 10 years to obtain training up the Ophthalmology ST training pathway). (Survey ID 600$)$

I don't feel that I would want to leave the country, but the prospect of being paid less to carry out the same or worse antisocial hours is very depressing. I hadn't considered GP until recently, and would only consider it purely for a better quality of life. (Survey ID 207)

Specific job characteristics of acute hospital specialties were cited as deterrents:

The contract issues have detracted me from considering core medical training due to the likely increase in antisocial hours. (Survey ID 151)

Emergency medicine was joint first choice-but the new contract seems to penalise emergency medicine doctors even more than before.' (Survey ID 249)

However, a number of junior doctors also expressed negative perceptions of training in a community-based GP role because of perceived specific adverse effects of proposed contract changes:

uncertainty over salaries for GP trainees has made me re-consider whether it will be a suitable job for me as I am considering whether I will be able to afford bills/ debts etc. (Survey ID 47)

\section{Response E-stick; proceed to apply for preferred specialty}

Almost two-thirds of respondents indicated no change in the first choice specialty, with no statistically significant difference between these proportions among those applying to acute hospital roles $(62.9 \%)$ and community roles $(62.8 \%)$.

Among those who commented that contract issues have not made a difference to their career plans, reasons were built on previous certainty and clear preferences:

I feel that my choice of career will be intrinsically motivated ie, it will match my career values and interests. These will not change with the contract (Survey ID 24)

Job satisfaction is paramount, so I'm sticking to the specialty which gives me this. The contract doesn't change that. (Survey ID 679)

Eventually I will have to apply as I want to further my career, so really it does not make a huge difference. (Survey ID 18)
However, while recognising that their specialty choice was unaffected, significant evidence emerged of a shift in doctors' attitudes and concerns for the future because of the contract issues:

Hasn't changed my first choice of applying for [Core Medical Training] but it will make me think twice about specialising in something that will involve acute medicine as I know the hours and pressure will only get worse. (Survey ID 329)

They haven't influenced my choice of specialism, but certainly have made me consider about my long term future within the NHS (Survey ID 761)

I don't think many people are changing their speciality choices because of the contracts but they're questioning the bigger question of whether or not you want to be a doctor in the UK in the NHS. (Interviewee ID GP1P14)

\section{Combinations of mitigating responses}

The strategies identified through this survey need not be mutually exclusive; for example, a doctor could postpone training while also intending to move abroad. The breakdown of the sample in table 5 shows that eight respondents, who stated that they intend to prepare for a career in an acute hospital role, indicated that factors related to the contract have played a role in their decisions to adopt multiple strategies; to defer their training application, to change their preferred training scheme and made it likely that they will move abroad to progress their career.

Response combinations involving changing specialty are more frequently selected than those which do not include this switch response. Furthermore, only a combination which includes exiting and switching shows statistical difference between those indicating an acute hospital preference versus those who indicate a community role.

I had already decided I wanted to take a career break but the contract discussions have made me look into options other than returning to medicine in the UK after thismy partner and I are now considering emigrating permanently. (Survey ID 513)

I am deferring training as I am considering emigrating to practice overseas. If the new contract came in I would definitely leave the NHS. Even then I am uncertain if I wish to continue practicing medicine in a system and country which completely undervalues its healthcare system and staff (Survey ID 783)

\section{DISCUSSION}

\section{Principal findings}

We find evidence of systematic changes in the training and career plans among F2 respondents applying for a ST programme amidst the contract dispute. We identify four responses among F2s, employed either singly or in 
Table 5 Combinations of mitigating responses to the proposed new contract

\begin{tabular}{|c|c|c|c|c|c|c|c|c|c|}
\hline & \multicolumn{2}{|l|}{$\begin{array}{l}1 \text { Acute } \\
\text { hospital }\end{array}$} & \multicolumn{2}{|l|}{$\begin{array}{l}2 \text { Other } \\
\text { hospital }\end{array}$} & \multicolumn{2}{|c|}{3 Community } & \multicolumn{2}{|l|}{ Total } & \multirow{2}{*}{$\begin{array}{l}\text { Difference between } \\
1 \text { and } 3\end{array}$} \\
\hline & Number & Col \% & Number & Col \% & Number & Col \% & Number & Col \% & \\
\hline No mitigation (0) & 286 & 62.9 & 66 & 68 & 115 & 62.8 & 467 & 63.5 & $0.1(-8.3$ to 8.3$)$ \\
\hline Defer only (1) & 54 & 11.9 & 4 & 4.1 & 7 & 3.8 & 65 & 8.8 & $8.0(4$ to 12.1$)$ \\
\hline Train and leave only (1) & 29 & 6.4 & 3 & 3.1 & 4 & 2.2 & 36 & 4.9 & $4.2(1.1$ to 7.3$)$ \\
\hline Change specialty only (1) & 33 & 7.3 & 14 & 14.4 & 32 & 17.5 & 79 & 10.7 & $-10.2(-16.2$ to -4.2$)$ \\
\hline $\begin{array}{l}\text { Defer and train and } \\
\text { leave (2) }\end{array}$ & 11 & 2.4 & 3 & 3.1 & 2 & 1.1 & 16 & 2.2 & $1.3(-0.7$ to 3.4$)$ \\
\hline $\begin{array}{l}\text { Defer and change } \\
\text { specialty (2) }\end{array}$ & 20 & 4.4 & 2 & 2.1 & 11 & 6 & 33 & 4.5 & $-1.6(-5.5$ to 2.3$)$ \\
\hline $\begin{array}{l}\text { Train and leave and } \\
\text { change specialty (2) }\end{array}$ & 14 & 3.1 & 5 & 5.2 & 12 & 6.6 & 31 & 4.2 & $-3.5(-7.4$ to 0.4$)$ \\
\hline $\begin{array}{l}\text { Defer, train and leave and } \\
\text { change specialty ( } 3 \text { ) }\end{array}$ & 8 & 1.8 & 0 & 0 & 0 & 0 & 8 & 1.1 & 1.8 (0.6 to 3$)$ \\
\hline Total & 455 & 100 & 97 & 100 & 183 & 100 & 735 & 100 & \\
\hline
\end{tabular}

Numbers in parentheses represent the number of mitigating responses employed.

$95 \% \mathrm{Cls}$ are provided in ().

combination. Some postponed making a firm decision by taking a break from training ('defer': $17 \%$ ), some changed their first choice of ST programme to ameliorate the contract's impacts during training and/or their subsequent career ('switch': 20\%). Some indicated they would complete training but intended to leave the UK later ('train and leave': 12\%) while some others do not intend to undertake future medical training or work in the UK ('exit': 4\%). There was variation in the prevalence of these responses between designated categories of training programmes (acute hospital, other hospital, community-based). The switching of first choice training preferences was greatest among those opting for a community-based specialty; indeed $30 \%$ of sampled F2s applying to train in general practice had switched their specialty choice which could mark a shift in recent recruitment patterns.

While choosing to defer progression to specialty training need may simply allow doctors more time and additional experience to better inform their eventual specialty decisions, there is a risk that any extended period of absence from UK medical work could make it more difficult for them to return or increase the chances that they become involved in an alternative career.

\section{Strengths and weaknesses of the study}

The response rate for the survey was $12.6 \%$ of all eligible F2s. However, we are unable to confirm whether an invitation to participate was received by F2s who did not respond. The achieved response rate is comparable to other studies in the research field and highlights the difficulty in engaging busy junior doctors. For example, while the MABEL survey in Australia reports a $19.4 \%$ response rate to their 2008 survey of Australian physicians, Cleland et al reports an $8 \%$ UK-wide response rate of medical trainees. ${ }^{28} 29$
IP address checks have not raised concerns that individuals may have repeatedly completed the survey. Response rates varied between FSs which may be partly due to the engagement of the FS with the study and the distribution method used. Analysis of samples based on the response rate at respondents' FSs, revealed no significant difference between contract-related effects on the decision to move abroad, defer training or change preference across FSs with higher or lower response rates.

Although the spread of preferred career choices broadly matched recent patterns, the sample contained relatively more women that the cohort as a whole. While this gender shift could produce sample averages that are not representative of the entire population, our interest is in the relationships between variables or differences between groups. The importance of this distinction is evident in work by Gravelle et $a l l^{30}$ which demonstrated that although response bias may affect mean values, this effect does not necessarily apply to relationships between variables within the sample data. Further, although we recognise that the proportion of women completing the survey was greater than their presence in this cohort $(65 \%$ vs $56 \%)$, no statistically significant difference was demonstrated (by $\chi^{2}$ and Fisher's exact tests) between sampled men and women choosing acute, other hospital or community ST programmes. Similarly, we confirmed no significant difference in how sampled men and women reported their intentions to defer, change and move abroad.

Data collection coincided with an evolving, escalating and disruptive industrial dispute. To decrease the chances of our survey being used as a platform to register dissatisfaction with the contract, invitations to participate focused on the general topics of career preferences and plans, avoiding reference to the contract. We therefore believe it unlikely that respondents represent a 
group which is self-selected because of their views on this point.

Data collected during the dispute, when many of those involved were undertaking strike action, are likely to reflect heightened emotions which may dissipate over time. However, the decisions that they made then may have lasting consequences for themselves, for the NHS workforce and for the profession as a whole. While it is not possible to determine the durability of individual career intentions, the survey presented no incentive for misleading responses. Further, subanalysis indicated that, at the point of completion of the survey, $45 \%$ of our sample had already applied so data refers to actual applications, not intentions. For the remaining $55 \%$, the timing of the survey meant that they were approaching the point at which they must apply and therefore likely to have already thought through these issues. Patterns of application across the three specialty groups are broadly similar whether they are intended or actual applications. While we recognise that intentions are not the same as actual recruitment into the specialty training courses, they give us an early indication of likely patterns and choice, influential factors are developed further in qualitative data.

Although we obtained data on whether respondents had switched specialty programme, we do not know from which programme they had switched. This restricts analysis of the specialty substitution effects of the contract. Nonetheless, as we argued when discussing Mitigating Response D (switch training programme), it appears that contractual negotiations led to a significant proportion of respondents who would have previously applied for acute hospital roles, now indicating their preference for community roles. As a result, we believe the 'switch' mitigating response proportions for community-based careers may be inflated by doctors switching to community-based programmes. However, we do not have details about how their preferences changed and therefore cannot fully disentangle these figures, and this is a limitation of the study.

\section{STRENGTHS AND WEAKNESSES IN RELATION TO OTHER STUDIES, DISCUSSING IMPORTANT DIFFERENCES IN RESULTS}

We have been unable to identify any published comparable studies of intention to choose a particular specialist programme as reported by doctors reaching this point in their training. However, these results are consistent with evidence that contemporary junior doctors are more likely than their predecessors to choose a career which will fit with their lifestyle and personal aspirations, and this is related to feeling enthusiastic about their future work. ${ }^{31}$ Studies which have focused on specific sites of influence when exploring factors behind medical career decision-making have not elicited evidence of the influence of contractual issues such as those we report here. ${ }^{32} 33$
A lack of similar studies prevents comparison of these findings against data collected in the absence of a contractual change or industrial dispute when other factors may have affected career choices. Reports of recruitment for recent F2 cohorts have shown a gradual decline in the proportion of doctors proceeding immediately into specialist training; dropping from $71.3 \%$ in 2011 to $52 \%$ in $2015 .{ }^{4}$ It remains to be confirmed whether the higher level $(61 \%)$ of participants in this study who stated that they intended to apply to begin specialist training in 2016 do actually enter training programmes or whether failure to access their preferred specialty, or other factors, may reduce those occupying training posts. However, indications that doctors have switched to community-based training as a response to proposed contract changes, are consistent with an increase in the 2016 intake for Health Education England (HEE) GP training programmes and decreases in acute hospital ST programmes. $^{34}$

Additional information sources will, in due course, provide information on specific points; medical schools report on the career destinations of their graduates and FS annual career destination reports will show the numbers of F2 doctors immediately progressing to ST/ CT posts or alternative post-FP plans. While HEE will publish information on fill-rates for ST/CT posts, these figures do not discriminate between doctors proceeding directly from FPs, previous FP cohorts returning to undertake ST and doctors entering the UK. Further developing sources of information which track the career paths of those doctors (eg, http://www.ukmed.ac. $\mathrm{uk} /$ ) may add useful information about doctors who have left the UK but this is not yet a comprehensive database.

Importantly, none of these sources can provide the contextually-relevant information which is necessary to understand the reasons behind observed trends and career trajectories. Lack of both context and contributory factors therefore limits information available to inform strategic responses which will enhance balanced recruitment and encourage retention of trained doctors at an early stage in career development. When rota gaps and low recruitment in some specialisms are already causing concern, it is vital that these aspects are considered when interpreting emerging data and to reveal the extent and depth to which the new contract or the still unresolved dispute has affected this sample and its potential knock-on effects on subsequent cohorts. Evidence of a rising level of $\mathrm{F} 2$ doctors not immediately proceeding to specialist training suggests that, once trends are established they may become difficult to reverse.

Official statements and actions surrounding this contractual renegotiation and dispute have conveyed to junior doctors a message which makes them feel that their efforts are unrecognised and that they are under-valued. As a result, some have become disenchanted with the notion of working hard for the privilege of being a respected medical professional. A critical issue will be whether these 
feelings are confined to the cohort experiencing the change. If not, then a diminishing level of willingness to work in this way may also affect their senior and junior colleagues, bringing more widespread effects throughout the medical workforce. This risk is magnified by the ongoing failure to resolve the dispute. This effect would contrast with objectives initially identified for the contract, which included more engaged and valued doctors and improved relationships between doctors and employers.

\section{Unanswered questions and future research}

The study involves stated preference data from trainees about what they have done or will do. Once data are available on observed training places filled then analysis of the impact of the contract on this cohort can be extended, although that data will not include information on changes in choices and underlying motivations.

Traditional sources of information on specialty choice; for example, from Academic Royal Colleges, BMA, regional career support programmes and a range of toolkits and publications, ${ }^{35-37}$ will have been of less use than usual for this cohort because of their focus on personal characteristics and job attributes with scant attention paid to conditions of employment. The choices made by F2s this year are affected by a combination of the contract itself and the uncertainty around it. Uncertainty regarding the new contract's effects on employment conditions will likely reduce over time, although the contract's impacts may still be large.

Given that early career choices have been highly predictive of eventual careers, ${ }^{38}$ decisions made in the heat of a turbulent time may have significant consequences for the availability and engagement of the future medical workforce. In addition to the effects of the mitigating strategies described above, significant effects observed in this study extend beyond evidence altered career choices. Any effects in training choices and career plans identified among this cohort may be a temporary effect or may indicate a transition to new patterns of specialty choice. The scale and duration of those effects can only be identified by analysis of future cohorts' training choices and the composition of the future medical workforce.

If multiple reported stressors are, in the future, prevalent in the NHS workplaces due to medical staff shortages, limited training support and feeling undervalued, there is a risk that low levels of morale and engagement will increase costs of service delivery. ${ }^{39} 40$ Doctors are already aware that their knowledge, skills and training are highly marketable around the world and, if conditions appear unfavourable, greater numbers may leave the NHS to take advantage of opportunities overseas. It is clear that this dispute has left many junior doctors feeling that they are not valued in the NHS, and to avoid further instability in the NHS medical workforce it will be important to repair fractured relationships as quickly as possible. Furthermore, leaving aside the specifics of the recent contractual dispute, the free text and interview responses that we have elicited in this study suggest that Foundation doctors often do not feel ready to commit themselves to a particular training path. Inherent rigidity in UK ST programmes can make it difficult to switch between specialties. This inflexibility heightens junior doctors' concern about making a career decision which is good for their own future and limits capacity to rapidly alter the balance of specialties in the workforce in response to future NHS priorities. It may be useful to investigate whether specialty training in the NHS could be made more attractive by adjustments that make it easier to switch paths during training.

\section{CONCLUSIONS}

The main purpose of this paper is to provide an early indication of how the career decisions of junior doctors have been shaped by the terms of and uncertainty surrounding a new employment contract and to examine the reasons behind their decisions. Survey data has indicated that a proportion of doctors have altered their immediate and/or longer term career plans with some switching to specialist programmes which they perceive will be less adversely affected by expected contractual changes. Further, it is evident from interview data that doctors who feel under-valued, unsupported or uncertain, are prepared to reconsider their wish to work in the NHS and to revise their career plans.

Since the effectiveness of the NHS depends on longterm employment of a balanced range of specialists, it is vital that future generations of doctors believe that their future lies in jobs which fulfil the requirements of NHS activities. There is therefore, great value in early access to knowledge of the contextual factors which influence these decisions, to inform interpretation of emerging recruitment data for all specialist training programmes and facilitate more constructive responses from medical schools, foundation schools and NHSE to mitigate detrimental impact on the NHS medical workforce.

Contributors SS, JG, DR, MS and KC designed and organised distribution of the survey questionnaire and analysis of findings. EP and SS conducted interviews. EP analysed comments and transcripts in discussion with SS. All have contributed to writing, reviewing and finalising this manuscript. SS is Principal Investigator for this study and the guarantor.

Funding This paper presents independent research funded by the National Institute for Health Research School for Primary Care Research (NIHR SPCR) Grant No 260. The views expressed are those of the author(s) and not necessarily those of the NHS, the National Institute for Health Research of the Department of Health.

Competing interests None declared.

Ethics approval Ethics approval was granted through the University of Manchester Research Ethics Committee 6, Ref: ethics/15370.

Provenance and peer review Not commissioned; externally peer reviewed.

Data sharing statement Data in this study is drawn from a larger study. Within constraints from NHIR, and any publishing or ethical considerations restrictions, we will endeavour to respond to requests for additional data. Any such requests should be directed to the first author. 
Open Access This is an Open Access article distributed in accordance with the Creative Commons Attribution Non Commercial (CC BY-NC 4.0) license, which permits others to distribute, remix, adapt, build upon this work noncommercially, and license their derivative works on different terms, provided the original work is properly cited and the use is non-commercial. See: http:// creativecommons.org/licenses/by-nc/4.0/

\section{REFERENCES}

1. BMA. Timeline for junior doctors contract negotiations. 2016. http:/ www.nhsemployers.org/your-workforce/pay-and-reward/nationalnegotiations/timeline-for-junior-doctors-contract-negotiations (accessed on 20 May 2016)

2. Madden GBP, Madden AP. Has modernising medical careers lost its way? BMJ 2007;335:426-8.

3. Fuller G, Simpson IA. "Modernising Medical Careers" to "Shape of Training"--how soon we forget. BMJ 2014;348:g2865.

4. UK Foundation Programme Office. F2 Career Destination Report 2015. UK Foundation Programme, 2015.

5. NHS Employers. Scoping report on the contract for doctors in training-June 2011. London: The NHS Confederation (Employers) Company, 2011.

6. Doctors and Dentists Review Body. Review Body on Doctors' and Dentists' Remuneration; Contract reform for consultants and doctors \& dentists in training - supporting healthcare services seven days a week. July 2015; Available from: https://www.gov.uk/government/ uploads/system/uploads/attachment data/file/445742/50576_DDRB report_2015_WEB_book.pdf

7. Cowper A. Megaphone diplomacy fails in junior doctor contract dispute. BMJ 2016;352:i961.

8. UK Parliament. Commons Debate: Junior Doctors Contract. 2016; Available from: http://www.publications.parliament.uk/pa/cm201516/ cmhansrd/cm160211/debtext/160211-0002.htm\#16021153000002

9. Dyer C. Bitter dispute leads junior doctors to take unprecedented action. BMJ 2016;353:i2404.

10. BMA. DDRB recommendations-analysis for juniors. 2016. https:// www.bma.org.uk/collective-voice/influence/key-negotiations/ terms-and-conditions/junior-and-consultant-contract-home/ ddrb-recommendations-analysis-for-juniors

11. BMA. Junior doctor contract negotiations. 2016. http://www.bma.org uk/working-for-change/junior-and-consultant-contract-home/ ddrb-recommendations-analysis-for-juniors

12. McCartney M. Margaret McCartney: a sexist contract for junior doctors. BMJ 2016;353:i1943.

13. Department of Health. Equality Analysis on the new contract for doctors and dentists in training in the NHS 2016; Available from: https://www.gov.uk/government/uploads/system/uploads/ attachment data/file/512696/jd-eia.pdf.

14. McKay AJ, Parekh R, Majeed A. Implications of the imposition of the junior doctor contract in England. J R Soc Med 2016;109:128-30.

15. Ipsos MORI and BMA. Doctors in training - contract proposals. London: Ipsos MORI and British Medical Association, 2013.

16. Meghii S, Rajan N, Philpott J. What does the junior contract mean for me, my patients and the NHS? J $R$ Soc Med 2015;108:470-1.

17. Neville, S. UK junior doctors: Jeremy Hunt imposes new contract. Financial Times 2016 February 11, 2016 1:15pm; Available from: https://www.ft.com/content/977018d4-d0b7-11e5-831d $09 f 7778$ e7377

18. Triggle N. We will fight contract imposition, says BMA. BBC website, 2016.

19. Godlee F. Breaking point. BMJ 2016;353:i2260.

20. Osborne, S. and A. Withnall. Junior doctors strike: Majority of public support doctors ahead of first full walkout, poll shows. Independent 201626 April 2016; Available from: http://www.independent.co.uk/ news/uk/politics/majority-of-public-support-junior-doctors-ahead-offirst-full-walkout-poll-shows-a7000751.htm

21. Moberly, T. and A. Rimmer. Royal colleges work to broker a junior contract deal. BMJ Careers 201619 Apr 2016; Available from: http://careers.bmj.com/careers/advice/Royal_colleges_work_to broker_a_junior_contract_deal

22. Gayle D. Junior doctors strike will not put patients at risk, say senior medics, in The Guardian. UK edition, 2016.

23. Braun V, Clarke V. Using thematic analysis in psychology. Qual Res psychol 2006;3:77-101.

24. Rodriguez-Santana Idaira, Martin C. The socioeconomic and demographic characteristics of United Kingdom junior doctors in training across specialities. UK: Centre for Health Economics, University of York, 2015. http://www.york.ac.uk/media/che/ documents/papers/researchpapers/CHERP_119_junior_doctors training_specialities.pdf

25. Dossajee H, Obonyo N, Ahmed SM. Career preferences of final year medical students at a medical school in Kenya-a cross sectional study. BMC Med Educ 2016;16:5.

26. UK Foundation Programme Office. Foundation Programme Annual Report 2015. 2015; Available from: http://www.foundationprogramme. nhs.uk/download.asp?file=FP_Annual_Report_2015_-_FINAL.pdf

27. Health Education England. Specialty recruitment: round 1acceptance and fill rate. 2016 [cited 01 Jul 2016]. https://hee.nhs.uk/ our-work/attracting-recruiting/medical-recruitment/specialtyrecruitment-round-1-acceptance-fill-rate

28. Joyce CM, Scott $\mathrm{A}$, Jeon $\mathrm{SH}$, et al. The "Medicine in Australia: Balancing Employment and Life (MABEL)" longitudinal surveyprotocol and baseline data for a prospective cohort study of Australian doctors' workforce participation. BMC Health Serv Res 2010;10:50

29. Cleland J, Johnston $\mathrm{P}$, Watson $\mathrm{V}$, et al. What do UK doctors in training value in a post? A discrete choice experiment. Med Educ 2016;50:189-202.

30. Gravelle H, Hole AR, Hossain MI. Response bias in job satisfaction surveys: English general practitioners. Discussion papers in economics, 2008(2008/24).

31. Smith F, Lambert TW, Goldacre MJ. Factors influencing junior doctors' choices of future specialty: trends over time and demographics based on results from UK national surveys. J $R$ Soc Med 2015;108:396-405.

32. Al-Nuaimi Y, McGrouther G, Bayat A. Modernising medical careers and factors influencing career choices of medical students. Br J Hosp Med (Lond) 2008;69:163.

33. Shadbolt N, Bunker J. Choosing general practice-a review of career choice determinants. Aust Fam Physician 2009;38:53-5.

34. Health Education England. Specialty recruitment: round 1acceptance and fill rate. 2016 [cited 04 Aug 2016]. https://hee.nhs. uk/our-work/attracting-recruiting/medical-recruitment/ specialty-recruitment-round-1-acceptance-fill-rate

35. Windmills. Career choice and development support. [cited $29 \mathrm{Jul}$ 2016]. http://www.windmillsonline.co.uk/who-we-work-with/casestudies/national-deanery-career-management-support-for-doctors/

36. Gale RGJ. Sci59 online psychometric test; available via BMA [cited 2016]. https://www.bma.org.uk/advice/career/applying-for-training/ psychometric-test

37. Elton C, Reid J. The roads to success: a practical approach to career planning for medical students, foundation trainees (and their supervisors). 2012. http://cmec.info/wp-content/uploads/2011/07/ Roads-To-Success1.pdf

38. Goldacre MJ, Laxton L, Lambert TM. Medical graduates' early career choices of specialty and their eventual specialty destinations: UK prospective cohort studies. BMJ 2010;341:c3199.

39. Roland M, Everington S. Tackling the crisis in general practice. BMJ 2016;352:i942

40. Irish B, Purvis M. Not just another primary care workforce crisis.... $\mathrm{Br} J$ Gen Pract 2012;62:178-9. 